\title{
Prey Fragmentation and Transport in Six Tropical Arboreal Ant Species
}

\author{
Tadu Zephirin ${ }^{1, *}$, Messop-Youbi Edith Blandine ${ }^{1,2}$, Fomekong Lontchi Judicael ${ }^{1}$, \\ Alene Desiree Chantal ${ }^{1}$, Djieto-Lordon Champlain ${ }^{1}$ \\ ${ }^{1}$ Department of Animal Biology and Physiology, Faculty of Science, University of Yaoundé 1, Yaoundé, Cameroon \\ ${ }^{2}$ Department of Zoology and Animal Physiology, Faculty of Science, University of Buea, Buea, Cameroon \\ Email address: \\ zephirin_tadu@yahoo.ca (Tadu Z.), emessop@yahoo.fr (Messop-Youbi E. B.), judicaelfomekong@gmail.com (Fomekong L. J.), \\ chantalalene@yahoo.fr (Alene D. C.), champlain_djieto@yahoo.ca (Djiéto-Lordon C.) \\ ${ }^{*}$ Corresponding author
}

\section{To cite this article:}

Tadu Zephirin, Messop-Youbi Edith Blandine, Fomekong Lontchi Judicael, Alene Desiree Chantal, Djieto-Lordon Champlain. Prey Fragmentation and Transport in Six Tropical Arboreal Ant Species. Computational Biology and Bioinformatics.

Vol. 9, No. 1, 2021, pp. 21-30. doi: 10.11648/j.cbb.20210901.13

Received: May 17, 2021; Accepted: June 3, 2021; Published: June 25, 2021

\begin{abstract}
Prey fragmentation and transport modalities were studied in Myrmicaria opaciventris, Platythyrea conradti, Cremtogaster sp., Crematogaster clariventris, Tetramorium aculeatum and Oecophylla longinoda, six tropical ant species with varying levels of adaptation to foraging in the tree canopy. Termites and grasshoppers of different sizes were used as prey and deposited on a hunting arena. After prey capture, we investigated the strategy adopted by each ant species to fragment and transport their prey. The data were analyzed with classification tree, using Chi-squared Automatic Interaction Detection method to find the variation in prey fragmentation strategies and transportation modalities between arboreal ant species in relation with prey type and prey size. The results showed that prey fragmentation did not occur systematically after capture and varied between ant species with prey type and prey size. Studied ant species cut their prey either completely into tiny pieces or partially into two or three large pieces before cutting them totally into tiny pieces or not at all. Fragmentation strategy, induced variation in transport modalities including (a) transport of large pieces, each by a single worker; (b) transport of large pieces, each, by a group of workers; (c) transport of tiny pieces after total cutting, and (c) transport of entire prey in the nest without fragmentation. Prey fragmentation and transport modalities varied between ant species in relation with their level of adaptation to arboreal area.
\end{abstract}

Keywords: Ant, Prey Capture, Prey Fragmentation, Hunting

\section{Introduction}

In their environment, ants exploit diverse food items including prey, making them generalist predators, scavengers and omnivores [1]. Ants need to forage in their territory to find food. Foraging is thus the basis for the survival, development and reproduction of animals [2]. Prey capture involve the following behavioral acts: detection; attack and seizure; recruitment or not (depending of ant species); spread-eagling or not (depending of ant species and prey sizes), fragmentation (varies among ant species and prey sizes) and transport by a single worker or by several workers [1]. Recruitment of nestmates during prey capture appears to be a crucial stage that determines the success of the prey capture in many arboreal ant species. Nestmates are recruited using various mechanisms including (1) stochastic individual strategies by a single worker, (2) stochastic collective or tandem strategies found in ponerine ants [3], (3) group recruitment strategies with limited or (4) unlimited group sizes found in various myrmicine and formicine species [4, 5], and (5) leader-independent trail communication found in the formicine genus Polyrhachis [5]. After recruitment, huntresses of many arboreal ants species, cooperatively spread-eagle the prey. This prey is subsequently cut up before being transported as seen with Tetramorium aculeatum Mayr [6] and Crematogaster sp. [7]. In some arboreal ant species like Platythyrea conradti Emery [8] and 
Oecophylla longinoda Latreille [9], preys are transported to the nest without being cut up. Looking at the fragmentation approach adopted by many ant species, [10] found that workers of most arboreal ants cut-up large prey at the site retrieve them and bring smaller pieces to the nest while in most ground-living ant species, a group of workers retrieve large prey cooperatively without fragmentation with or without recruitment. From the above, we hypothesize that prey fragmentation and transport modalities varies in ant species with respect to their level of arboreal adaptation. To achieve this, we compared the fragmentation strategy during prey capture in six tropical ant species to find (1) the influence of prey type, prey size and morphological caste on the occurrence of prey fragmentation and (2) the influence of prey size on fragmentation strategy, and their implication in the transportation modalities.

\section{Material and Method}

\subsection{Study Site}

The study was conducted in the Minkoa Meyos orchard $\left(02^{\circ} 31^{\prime}, 10^{\circ} 55^{\prime}\right)$ near Yaoundé, and in the zoology laboratory at the University of Yaoundé 1, in Cameroon. Yaoundé is characterized by a subequatorial climate with a bimodal rainfall regime. The four distinct seasons are: two wet and two dry seasons. Rainfall averages is about $1700 \mathrm{~mm}$ per year and the mean annual temperature is about $25^{\circ} \mathrm{C}$. Minkoa Meyos orchard is an experimental station for fruits trees of "Institut de Recherche Agronomique pour le Développement (IRAD)". The orchard is comprised of Mangifera indica, Dacryodes edulis, Psidium goyava, Carica papaya, Elais guineensis, Citrus sinensis, Citrus limon, Citrus medica, planted in a regular spatial pattern. Plots of Zea mays, Manihot esculenta, Xanthosoma sp., Musa sapienta and Musa paradisiaca were intermingled haphazardly within the orchard.

\subsection{Studied ant Species}

The study was conducted on six ant species belonging to 3 sub-families (Formicinae, Myricinae, and Ponerinae) and 5 genera (Myrmicaria, Platythyrea, Crematogaster, Oecophylla and, Tetramorium). Ant species studied were selected according to their level of arboreal adaptation. We selected Myrmicaria opaciventris Emery, 1893 (Myrmicinae) a ground-dwelling ant species with arboreal habit [11], Platythyrea conradti Emery, 1899 (Ponerinae) a primitive arboreal ant species [8] and four ecologically dominant arboreal ant species found in great frequency of abundance and frequency of occurrence on the cocoa trees in agroforestry systems in south Cameroon [12, 13]: Crematogaster sp. (Myrmicinae) also call Crematogaster "tsapi" by [7], Crematogaster clariventris Mayr, 1895 (Myrmicinae), Tetramorium aculeatum Mayr, 1866 (Myrmicinae) and Oecophylla longinoda Latreille, 1802 (Formicinae).

\subsection{Experimental Apparatus}

\subsubsection{Ground-dwelling ant Species with Arboreal Habit}

Ground-dwelling ant species with arboreal habits are species that nest in the soil and forage in trees to collect floral and extrafloral nectars [11]. Experiments were conducted on 10 colonies of $M$. opaciventris within the Minkoa Meyos orchard. Two rectangular plywood sheets $(40 \times 40 \mathrm{~cm})$ were placed on the soil at three meters from the principal tunnel. The first plywood served as hunting arenas and the second as control.

\subsubsection{Primitive Arboreal Ant Species}

The colonies, of $P$. conradti were collected from traditional cocoa farms at Ngomedzap $\left(03^{\circ} 16^{\prime} \mathrm{N}, 11^{\circ} 13^{\prime} \mathrm{E}\right)$ around the Mbalmayo forest reserve, and Djazeng village $\left(02^{\circ} 31^{\prime} \mathrm{N}\right.$, $10^{\circ} 55^{\prime} \mathrm{E}$ ) in the Ntem valley and reared in the laboratory inside a "Chauvin" nest type. The colonies of $P$. conradti, lived inside the plant Platycerium epiphytes [8]. Prey foraging by $P$. conradti is most intense between 5:00 and 8:00 AM, while sugary substances are exploited between 5:00 AM and 17:00 PM [8]. Three parallelepiped boxes (each $25 \times 25 \times 5 \mathrm{~cm})$ covered by glass $(30 \times 30 \mathrm{~cm})$ were used. The central box serves as nesting box while the two others serve respectively as foraging and control arenas (Figure $1 \mathrm{~A} \& \mathrm{~B}$ ). Due to their rarity, just five colonies of $P$. conradti were collected from traditional cocoa farms.

\subsubsection{Specialized Arboreal Ant Species}

During field observations, we noted that $C$. clariventris and Crematogaster sp. forage mostly on the trunk while $T$. aculeatum and $O$. longinoda forage on the leaves surfaces. Because of this, a modified protocol of [6] used to study $T$. aculeatum predatory behavior was adopted. The protocol consists for attaching plywood sheets $(40 \times 51 \mathrm{~cm})$ to tree trunks at one meter above the ground (Figure 1C). For $T$. aculeatum and $O$. longinoda, leave surfaces of the host plant were used as experimental arenas (Figure 1D). The same protocol was applied to study recruitment rate of nestmate in arboreal ants by [14], which justify the presence of control arenas.

\subsection{Data Collection}

Prey was deposited on the hunting arena. After detection and capture, data collection consists of observing (1) if the prey was cutting or not before transport in the nest; when the cutting occurred (2) we investigated on the fragmentation strategies and transport modalities adopted. Termites and grasshopper of different size were used as prey. For termites, individual workers of 2-3 $\mathrm{mm}, 5-7 \mathrm{~mm}$ and soldiers of 5-8 $\mathrm{mm}$ in size were used; for grasshoppers individuals of 4-7 $\mathrm{mm}, 10-15 \mathrm{~mm}$ and $\geq 17 \mathrm{~mm}$ were enrolled. To prevent these grasshoppers from jumping, their tibia posterior legs were removed. Thirty interactions were observed for each prey size for a total of 180 observations for each prey type per ant species. No more than three cases were studied for each colony per day. 

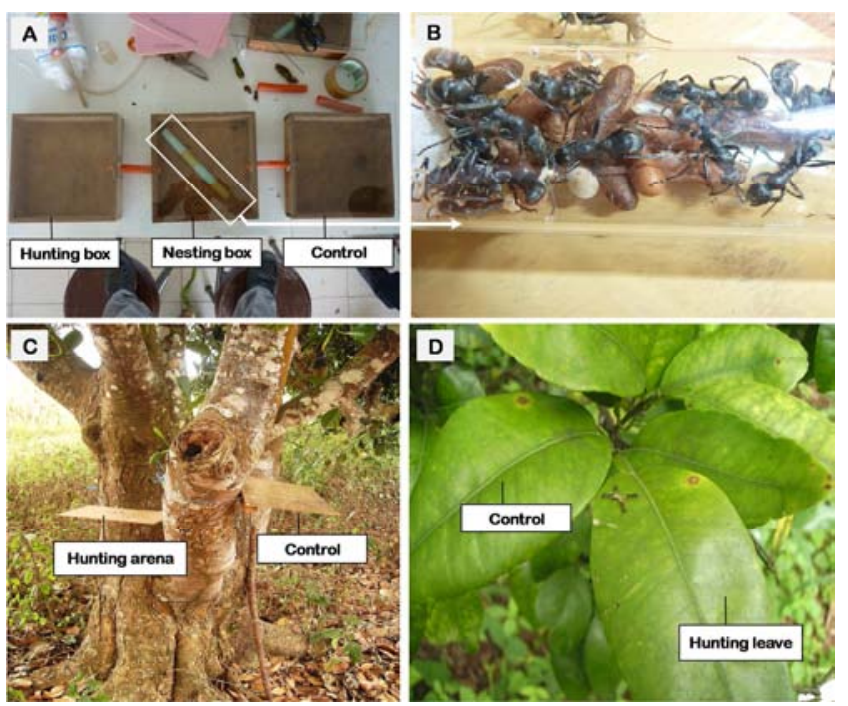

Figure 1. Experimental apparatus uses to study predatory behavior and fragmentation process of prey in arboreal ants $(A)$ and $(B)$ colony breeding in Platythyrea conradti, (C) Crematogaster $s p$. and Crematogaster clariventris and (D) for Oecophylla longinoda and Tetramorium aculeatum [14].

\subsection{Data Analysis}

We tested the main effect of prey type, morphological caste and prey size on the variation of fragmentation occurrence between ant species using Chi-square tests (GLM Proc). Quantitative data were binary, so we applied binomial errors for the analysis. Analyses were done with R software (version 3.2.2.) and significance was attributed at the $5 \%$ level. The data were analyzed with classification tree, using Chi-squared Automatic Interaction Detection (CHAID) method to find the variation in prey fragmentation strategies and transportation modalities between arboreal ant species in relation with prey size and prey type.

CHAID is a type of decision tree technique for nominal scale dependent variable. We considered ant species as an independent variable; prey size, fragmentation strategies, and number of piece after prey cutting were use as dependent categorical variables. The tree starts with an initial node composed by all the observations and the others correspond for each, to one modality of a considered dependent variable. Chi-square test was used for separation of the best variable. This test helped to separate observations in two groups which lead to the creation of a new node. The same analysis was conducted on the new node and created another node. When the number of observations is not sufficient to create a new node, the analysis stops. The interest of this analysis relies principally on the fact that it permits to organize into a hierarchy dependent variables based on their influence on independent variables in order to show existing interactions between all these variables. The tree classification analysis was run using SPSS 19.0 software and significance was attributed at the $5 \%$ level.

\section{Results}

\subsection{Effect of Prey Type and Morphological Caste on Variation of Fragmentation Pattern}

In arboreal ant, fragmentation of prey was significantly influenced by prey type $\left(\chi^{2}=9.70 ; \quad \mathrm{df}=5 ; \quad \mathrm{P}<0.0001\right)$, morphological termite caste $\left(\chi^{2}=5.93 \mathrm{df}=5 ; \mathrm{P}<0.0001\right)$

Looking prey type, grasshoppers $(45.37 \%)$ were more frequently fragmented than termites $(20.00 \%)$. Crematogaster clariventris $(88.89 \%)$ followed by Crematogaster sp. (84.44\%) and T. aculeatum (67.78\%) fragmented grasshoppers more frequently than termites (Table 1). In relation with morphological caste, termite soldiers $(45.56 \%)$ were more frequently fragmented than workers (13.06\%). Crematogaster sp. (76.67\%), T. aculeatum (70.00\%), M. opaciventris $(70.00 \%)$ and C. clariventris $(53.33 \%)$ were frequently fragmented termite soldiers than workers (Table 1).

Table 1. Variation of fragmentation occurrence with prey type and termite caste.

\begin{tabular}{|c|c|c|c|c|c|c|c|c|}
\hline \multirow{3}{*}{ Ant species } & \multicolumn{4}{|l|}{ Prey type } & \multicolumn{4}{|c|}{ Termite caste } \\
\hline & \multicolumn{2}{|c|}{ Grasshoppers } & \multicolumn{2}{|l|}{ Termites } & \multicolumn{2}{|c|}{ Workers } & \multicolumn{2}{|l|}{ Soldiers } \\
\hline & A & B & A & B & A & B & A & B \\
\hline Crematogaster clariventris & $10(11.11)$ & $80(88.89)$ & $62(68.89)$ & $28(31.11)$ & $48(80.00)$ & $12(20.00)$ & $14(46.67)$ & $16(53.33)$ \\
\hline Crematogaster sp. & $14(15.56)$ & $76(84.44)$ & $42(46.67)$ & $48(53.33)$ & $35(58.33)$ & $25(41.67)$ & $7(23.33)$ & $23(76.67)$ \\
\hline Tetramorium aculeatum & $29(9.83)$ & $61(67.78)$ & $61(67.78)$ & $29(32.22)$ & $58(86.67)$ & $2(13.33)$ & $9(30.00)$ & $21(70.00)$ \\
\hline Oecophylla longinoda & $83(92.22)$ & $7(7.78)$ & $89(98.89)$ & $1(1.11)$ & $60(100.00)$ & $0(0.00)$ & $29(96.67)$ & $1(3.33)$ \\
\hline Platythyrea conradti & $89(98.89)$ & $1(1.11)$ & $90(100.00)$ & $0(0.00)$ & $60(100.00)$ & $0(0.00)$ & $30(100.00)$ & $0(0.00)$ \\
\hline Myrmicaria opaciventris & $70(77.78)$ & $20(22.22)$ & $88(97.78)$ & $2(2.22)$ & $52(96.67)$ & $8(3.33)$ & $9(30.00)$ & $21(70.00)$ \\
\hline Total & $295(54.63)$ & $245(45.37)$ & $432(80.00)$ & $108(20.00)$ & $313(86.94)$ & $47(13.06)$ & $98(54.44)$ & $82(45.56)$ \\
\hline$\chi^{2}$ (GLM Proc) & \multicolumn{4}{|c|}{$\chi^{2}=9.70 ; \mathrm{df}=5 ; \mathrm{P}<0.0001$} & \multicolumn{4}{|c|}{$\chi^{2}=5.93 ; \mathrm{df}=5 ; \mathrm{P}<0.0001$} \\
\hline
\end{tabular}

A: no prey fragmentation; $\mathrm{B}$ : prey fragmentation; for each studied ant species $\mathrm{N}=90$ respectively for grasshopper and termites, $\mathrm{N}=60$ for workers and $\mathrm{N}=30$ for termite soldiers; the value into a bracket represent frequency of occurrence of fragmentation

\subsection{Effect of Prey Size on Variation of Fragmentation Pattern}

Frequency of fragmentation of termite increased significantly $\left(\chi^{2}=11.61 ; \mathrm{df}=10 ; \mathrm{P}<0.0001\right)$ with termite size. So, in termites, $2.78 \%$ of $2-3 \mathrm{~mm}$ sized prey were fragmented while $33.89 \%$ of $5-8 \mathrm{~mm}$ sized prey were fragmented. The highest fragmentation rate was observed in termites of 5-8 mm size for Crematogaster sp. (76.67\%), T. aculeatum (70.00\%) and C. clarientris (53.33\%) (Table 2). 
Table 2. Variation of prey fragmentation occurrence with prey sizes in presence of termites.

\begin{tabular}{|c|c|c|c|c|c|c|}
\hline \multirow{3}{*}{ Ant species } & \multicolumn{6}{|l|}{ Termites } \\
\hline & \multicolumn{2}{|l|}{$2-3 \mathrm{~mm}$} & \multicolumn{2}{|l|}{$5-7 \mathrm{~mm}$} & \multicolumn{2}{|l|}{$5-8 \mathrm{~mm}$} \\
\hline & A & B & A & B & A & B \\
\hline Crematogaster clariventris & $28(93.33)$ & $2(6.67)$ & $20(66.67)$ & $10(33.33)$ & $14(47.67)$ & $16(53.33)$ \\
\hline Crematogaster sp. & $28(93.33)$ & $2(6.67)$ & $7(23.33)$ & $23(76.67)$ & $7(23.33)$ & $23(76.67)$ \\
\hline Tetramorium aculeatum & $30(100.00)$ & $0(0.00)$ & $22(73.33)$ & $8(26.67)$ & $9(30.00)$ & $21(70.00)$ \\
\hline Oecophylla longinoda & $30(100.00)$ & $0(0.00)$ & $30(100.00)$ & $0(0.00)$ & $29(96.67)$ & $1(3.33)$ \\
\hline Platythyrea conradti & $30(100.00)$ & $0(0.00)$ & $30(100.00)$ & $0(0.00)$ & $30(100.00)$ & $0(0.00)$ \\
\hline Myrmicaria opaciventris & $29(96.67)$ & $1(3.33)$ & $29(96.67)$ & $1(3.33)$ & $30(100.00)$ & $0(0.00)$ \\
\hline Total & $175(97.22)$ & $5(2.78)$ & $138(76.67)$ & $42(23.33)$ & $119(66.11)$ & $61(33.89)$ \\
\hline$\chi^{2}$ (GLM Proc) & \multicolumn{6}{|c|}{$\chi^{2}=11.61 ; \mathrm{df}=10 ; \mathrm{P}<0.0001$} \\
\hline
\end{tabular}

A: no prey fragmentation; B: prey fragmentation; for each studied ant species $\mathrm{N}=30$ for each prey size respectively; the value into a bracket represent frequency of occurrence of fragmentation

The same trend was observed in grasshoppers where fragmentation occurrence also significantly $\left(\chi^{2}=2.91 ; \mathrm{df}=10\right.$; $\mathrm{P}=0.003)$ increased with grasshopper size. Fragmentation occurrence, varied from $36.11 \%(4-7 \mathrm{~mm})$ to $54.44 \%(\geq 17$ $\mathrm{mm})$. The highest fragmentation rate was observed in Crematogaster sp. (96.67\%), C. clariventris (93.33\%) and $T$. aculeatum $(80.00 \%)$ for grasshoppers greater than $17 \mathrm{~mm}$ in size (Table 3).

Table 3. Variation of prey fragmentation occurrence with prey sizes in presence of grasshoppers.

\begin{tabular}{|c|c|c|c|c|c|c|}
\hline \multirow{3}{*}{ Ant species } & \multicolumn{6}{|c|}{ Grasshoppers } \\
\hline & \multicolumn{2}{|c|}{ 4-7mm } & \multicolumn{2}{|l|}{$10-15 \mathrm{~mm}$} & \multicolumn{2}{|l|}{$\geq 17 \mathrm{~mm}$} \\
\hline & $\mathbf{A}$ & B & $\mathbf{A}$ & B & $\mathbf{A}$ & B \\
\hline Crematogaster clariventris & $4(13.33)$ & $26(86.67)$ & $4(13.33)$ & $26(86.67)$ & $2(6.67)$ & $28(93.33)$ \\
\hline Crematogaster sp. & $13(43.33)$ & $17(56.67)$ & $0(0.00)$ & $30(100.00)$ & $1(3.33)$ & $29(96.67)$ \\
\hline Tetramorium aculeatum & $13(43.33)$ & $17(56.67)$ & $10(33.33)$ & $20(66.67)$ & $6(20.00)$ & $24(80.00)$ \\
\hline Oecophylla longinoda & $28(93.33)$ & $2(6.67)$ & $30(100.00)$ & $0(0.00)$ & $25(83.33)$ & $5(16.67)$ \\
\hline Platythyrea conradti & $30(100.00)$ & $0(0.00)$ & $30(100.00)$ & $0(0.00)$ & $29(96.67)$ & $1(3.33)$ \\
\hline Total & $115(63.89)$ & $65(36.11)$ & $98(54.44)$ & $82(45.56)$ & $82(45.56)$ & $98(54.44)$ \\
\hline$\chi^{2}$ (GLM Proc) & \multicolumn{6}{|c|}{$\chi^{2}=2.91 ; \mathrm{df}=10 ; \mathrm{P}=0.003$} \\
\hline
\end{tabular}

A: no prey fragmentation; B: prey fragmentation; for each studied ant species $\mathrm{N}=30$ for each prey size respectively; the value into a bracket represent frequency of occurrence of fragmentation

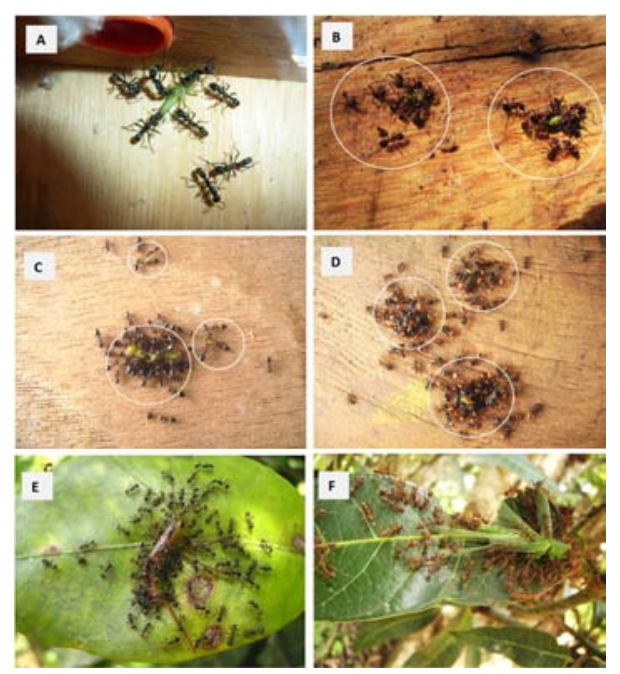

Figure 2. Prey fragmentation and transport modalities in tropical arboreal ant species. A: collective transport by Platythyrea conradti workers without prey fragmentation; B: fragmentation in two large pieces by Myrmicaria opaciventris worker, each large piece was transported by a group of worker; C: Partial fragmentation, followed by fragmentation in tiny pieces in Crematogaster sp.; D: prey fragmentation in three large pieces followed by fragmentation in tiny piece before collective transport in Crematogaster clariventris; E: Tetramorium aculeatum during spread-eagling before fragmentation in tiny pieces and collective transport and $F$ : partial fragmentation followed by collective transport of the prey by Oecophylla longinoda workers.

\subsection{Prey Fragmentation and Transport in Arboreal Ant}

In arboreal ants, preys were not systematically fragmented after capture; when necessary, they adopt various strategies to fragment their prey before transporting them. The following patterns was observed during prey fragmentation: (1) no fragmentation, frequently observed in M. opaciventris, $P$. conradti and $O$. longinoda in presence of small prey size (termite workers of 2-3 $\mathrm{mm}$ and $5-7 \mathrm{~mm}$ size and grasshopper of 4-7 $\mathrm{mm}$ size) where the prey was transported entirely in the nest by a single worker or collective workers (Figure 2A, 2F); (2) total fragmentation found in $T$. aculeatum, Crematogaster sp., and C. clariventris generally in presence of large prey size (termites soldiers of $5-8 \mathrm{~mm}$ size and grasshoppers of $10-15 \mathrm{~mm}$ and greater than $17 \mathrm{~mm}$ ) which involved some individuals totally dismembering their prey into tiny pieces before collective transport by workers (Figure 2E); (3) Partial fragmentation occurred with different sub-modalities including (3.1) appendages broken during spread-eagling found in O. longinoda (Figure 2C), in this case appendages and the rest of the prey were transported in the nest without further fragmentation by a worker; (3.2) prey fragmentation in two or three large pieces was noted in $M$. opaciventris (Figure 2B), each large piece was transported by a single worker or collectively by a group of workers; (4) 
Partial fragmentation followed by total fragmentation in tiny pieces found in C. clariventris, prey was fragmented into two or three large pieces first, after which, each large piece was fragmented into tiny pieces (Figure 2D) before being transported collectively by a group of workers.

\subsection{Fragmentation and Transport Modalities in Presence of Termites}

In presence of termites, the six ant species did not fragment their prey before transporting them to the nest in $80.0 \%$ of cases (Node 0, Figure 3). When fragmentation occurred, different strategies, were adopted, ant species were separated into three nodes significantly distinct $\left(\chi^{2}=184.406\right.$; $\mathrm{df}=6 ; \mathrm{P}<0.0001)$. Oecophylla longinoda, $P$. conradti and $M$. opaciventris were grouped in the node 1 ; these species rarely fragmented termite prey $(1.10 \%)$ before transportation. Crematogaster species and T. aculeatum were more likely to fragment prey (Node $2 \&$ Node 3, Figure 3). Crematogaster sp. adopted total and partial fragmentation respectively in $26.70 \%$ and $25.60 \%$ of observations of termite capture (Node 2, Figure 3). Crematogaster clariventris and T. aculeatum composed node 3 ; these species didn't cut termites in $68.30 \%$ of the cases; but totally fragmented in $24.4 \%$ of the total cases (Node 3, Figure 3). Prey transportation significantly changed depending on the fragmentation strategy adopted in C. clariventris and T. aculeatum $\left(\chi^{2}=81.58 ; \mathrm{df}=3 ; \mathrm{P}<\right.$ $0.0001)$. When termites were not fragmented by $C$. clariventris and T. aculeatum, their transport were done by a single worker or by a collective worker in $100 \%$ of the observed cases (Node 4, Figure 3). When fragmentation occurred, $C$. clariventris and $T$. aculeatum transported termites collectively in tiny pieces; sometimes, after partial fragmentation of appendages followed by the transport of the rest of entire prey. But they can also transport prey in a large piece either by a group of workers or by a single worker (Node 5, Figure 3).

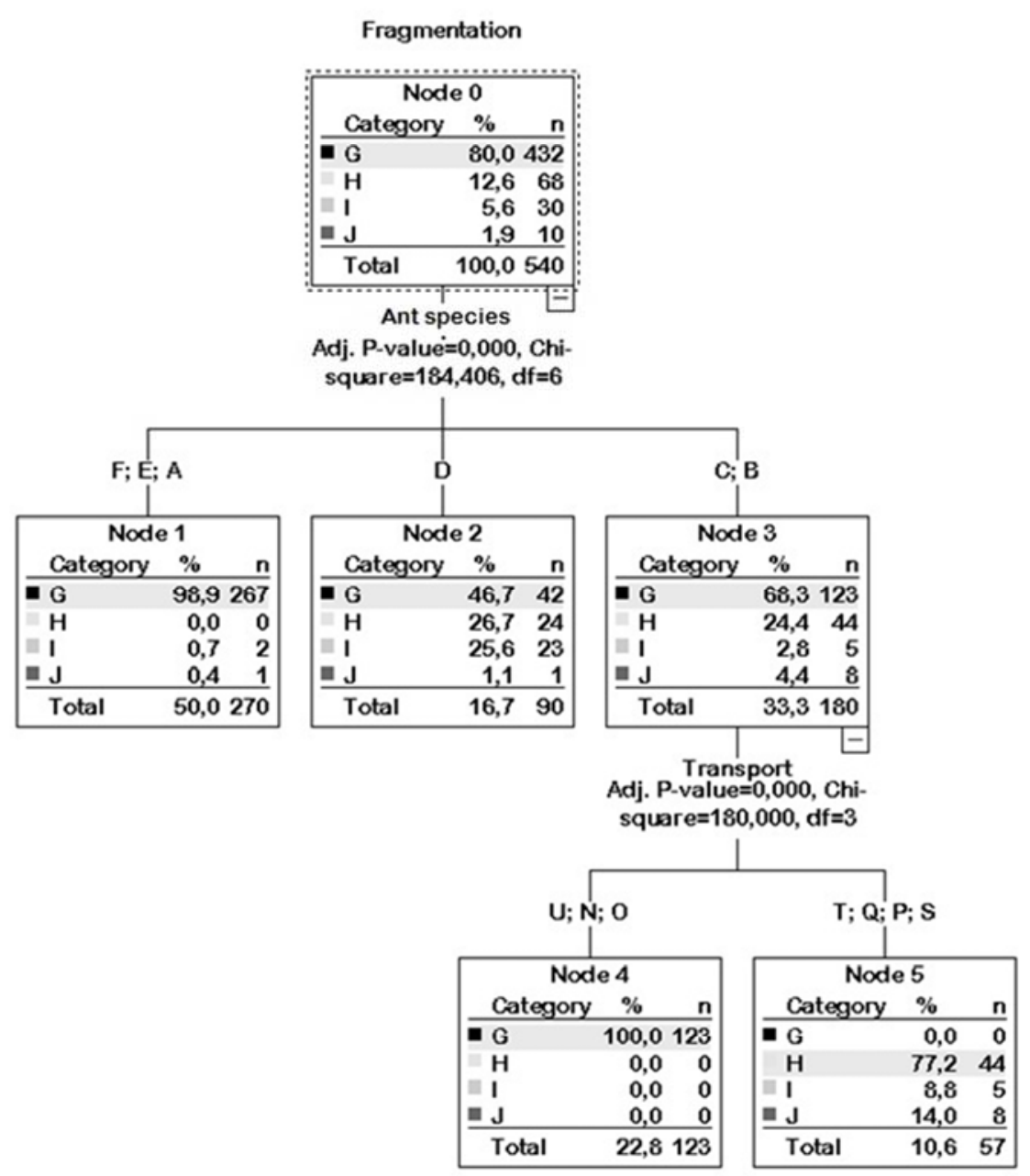

Figure 3. Tree diagram showing hierarchical influence between fragmentation strategy, prey size and transport modalities in six tropical arboreal ants in presence of termites.

\subsection{Variation of Number of Pieces During Termite Fragmentation}

Almost all termites prey were not fragmented into two or more large pieces before being transported (Node 0, Figure $4)$. On the basis of the strategy adopted, ant species were separated in two significantly distinct nodes $\left(\chi^{2}=9.985 ; \mathrm{df}=\right.$ $1 ; \mathrm{P}=0.049$ ). Node 1 (Figure 4) contained Crematogaster sp., 
O. longinoda, P. conradti and M. opaciventris. These species fragmented termites $(0.60 \%)$ into two large piece before transporting them. Node 2 (Figure 4) contained T. aculeatum and $C$. clariventris. With the exception of termite soldiers (5$8 \mathrm{~mm}, 1.7 \%$, Node 3, Figure 4$)$, in this group small prey $(2-3$ $\mathrm{mm})$ were less frequently fragmented (1. 7\%, Node 3, Figure $4)$ than larger prey $(5-7 \mathrm{~mm})$ which were more fragmented in large pieces in $10.0 \%$ of cases (Node 4 , Figure 4$)\left(\chi^{2}=6\right.$. $541 ; \mathrm{df}=1 ; \mathrm{P}=0.032)$.

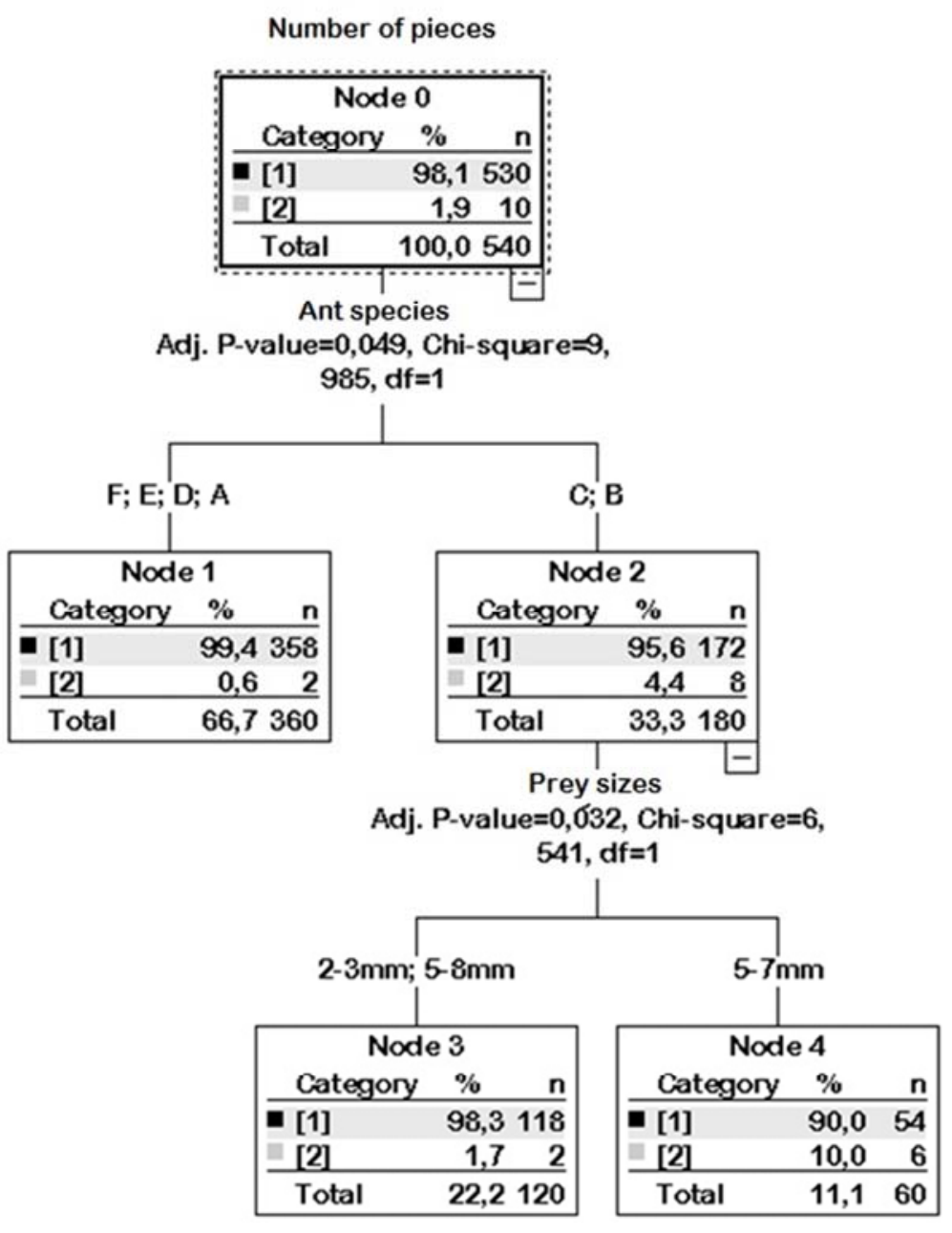

Figure 4. Tree diagram showing hierarchical influence between number of large pieces, ant species and prey size during prey fragmentation in six tropical arboreal ants in presence of termites.

\subsection{Fragmentation and Transport Modalities in Presence of Grasshopper}

When grasshoppers were the prey item no fragmentation was the most frequent approach observed in the six ant species studied $(54.6 \%)$ followed by fragmentation in tiny pieces (31.1\%) (Node 0, Figure 5). The fragmentation strategies varied significantly between ant species $\left(\chi^{2}=\right.$ 454.980; $\mathrm{df}=18 ; \mathrm{P}<0.0001)$, and four distinct groups of ant species were observed. The first node is composed of $M$. opaciventris (Node 1, Figure 5) in which no fragmentation was the most frequent strategy $(77.80 \%)$ followed by fragmentation in two large pieces $(18.90 \%)$. The second node (Node 2, Figure 5) is composed by $P$. conradti and $O$. longinoda. These species generally did not fragment their prey $(95.60 \%)$. Nevertheless, in very few case, O. longinoda partially fragmented $(7.80 \%)$ their prey during spreadeagling. Based on this, O. longinoda fragmentation strategy differed significantly from that of $M$. opaciventris $\left(\chi^{2}=8.209\right.$; $\mathrm{df}=2 ; \mathrm{P}=0.016$ ) (Figure 5). Node 3 (Figure 5) is composed of T. aculeatum and Crematogaster sp.. The most frequent fragmentation strategy adopted by these species was fragmentation in tiny pieces. In this group, prey size significantly influenced $\left(\chi^{2}=84.655 ; \mathrm{df}=3 \mathrm{P}<0.0001\right)$ the occurrence of fragmentation pattern. In grasshopper prey 4-7 $\mathrm{mm}$ in size the most frequent strategy was no fragmentation $(43.3 \%)$ while fragmentation in tiny pieces was the most frequent (84.2\%) for prey of $10-15 \mathrm{~mm}$ and $\geq 17 \mathrm{~mm}$ (Nodes $7 \& 8$, Figure 5). For prey size of $10-15 \mathrm{~mm}$ and $\geq 17 \mathrm{~mm}$ in Crematogaster sp. and T. aculeatum, fragmentation in tiny piece was significantly $\left(\chi^{2}=18.097 ; \mathrm{df}=3 \mathrm{P}<0.0001\right)$ more frequent in Crematogaster sp. (98.30\%) than in T. aculeatum (70.00\%) (Node 9\&10, Figure 5). Crematogaster clariventris formed a single group and had diverse prey fragmentation strategies although fragmentation in tiny pieces occurred frequently $(63.30 \%)$ (Node 4, Figure 5). 


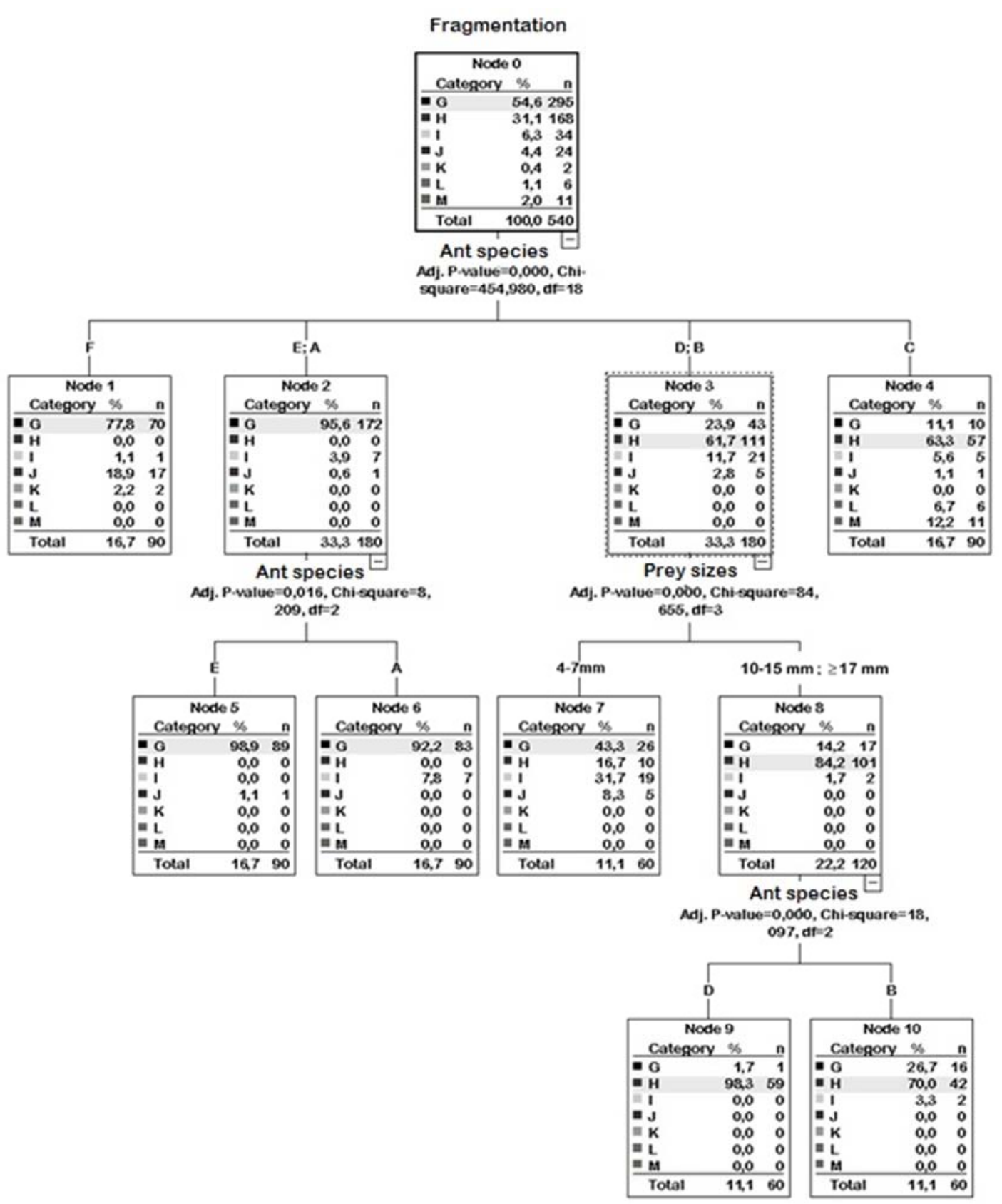

Figure 5. Trees diagrams showing hierarchical influence between fragmentation modalities, prey size and transport modalities in six tropical arboreal ants in presence of grasshoppers.

\subsection{Variation of Number of Pieces During Fragmentation of Grasshopper}

For grasshopper prey, the primary strategy $(92.0 \%)$ was to fragment prey in tiny pieces on the spot before transporting them or transport to the nest without fragmentation (Node 0, Figure 6). Fragmentation in two (5.60\%) large pieces was more frequent than fragmentation into three $(2.40 \%)$ large pieces before transport. Ant species were grouped into three significantly different nodes $\left(\chi^{2}=88.750 ; \mathrm{df}=4 ; \mathrm{P}<0,001\right)$. Node 1 contained $M$. opaciventris, node 2 four species including Crematogaster sp., O. longinoda, P. conradti and $T$. aculeatum and node 3 contained $C$. clariventris (Figure 6).
The most common approach in all groups was to exploit the prey without fragmentation. This represented $78.90 \%$, $98.30 \%$ and $80.0 \%$ of cases respectively for node 1 , node 2 and node 3 (Figure 6). Myrmicaria opaciventris (Node 1) fragmented grasshopper into two large pieces more frequently than species of node $2(O$. longinoda, $T$. aculeatum, Crematogaster sp. and $P$. conradti) and node 3 (C. clariventris) (Figure 6). Globally, O. longinoda, $T$. aculeatum, Crematogaster sp. and $P$. conradti shared approximately the same fragmentation strategy with $98.30 \%$ of the cases in which the prey was not fragmented into two or three large pieces (Node 2, Figure 6). In the last node, $\mathrm{Cr}$. clariventris fragmented their prey more frequently (12.20\%) 
into three large pieces compared to the other species (Nod 3, Figure 6). We also found a significant effect of prey size on the number of large pieces after fragmentation $\left(\chi^{2}=6.864\right.$; $\mathrm{df}=1 ; \mathrm{P}=0,035)$ in node 2 . In fact, grasshoppers prey size of
4-7 mm (Node 4, Figure 6) were less frequently exploited in one piece $(95.8 \%)$ than prey size of $10-15 \mathrm{~mm}$ and $\geq 17 \mathrm{~mm}$ (99.60\%) (Node 5, Figure 6).

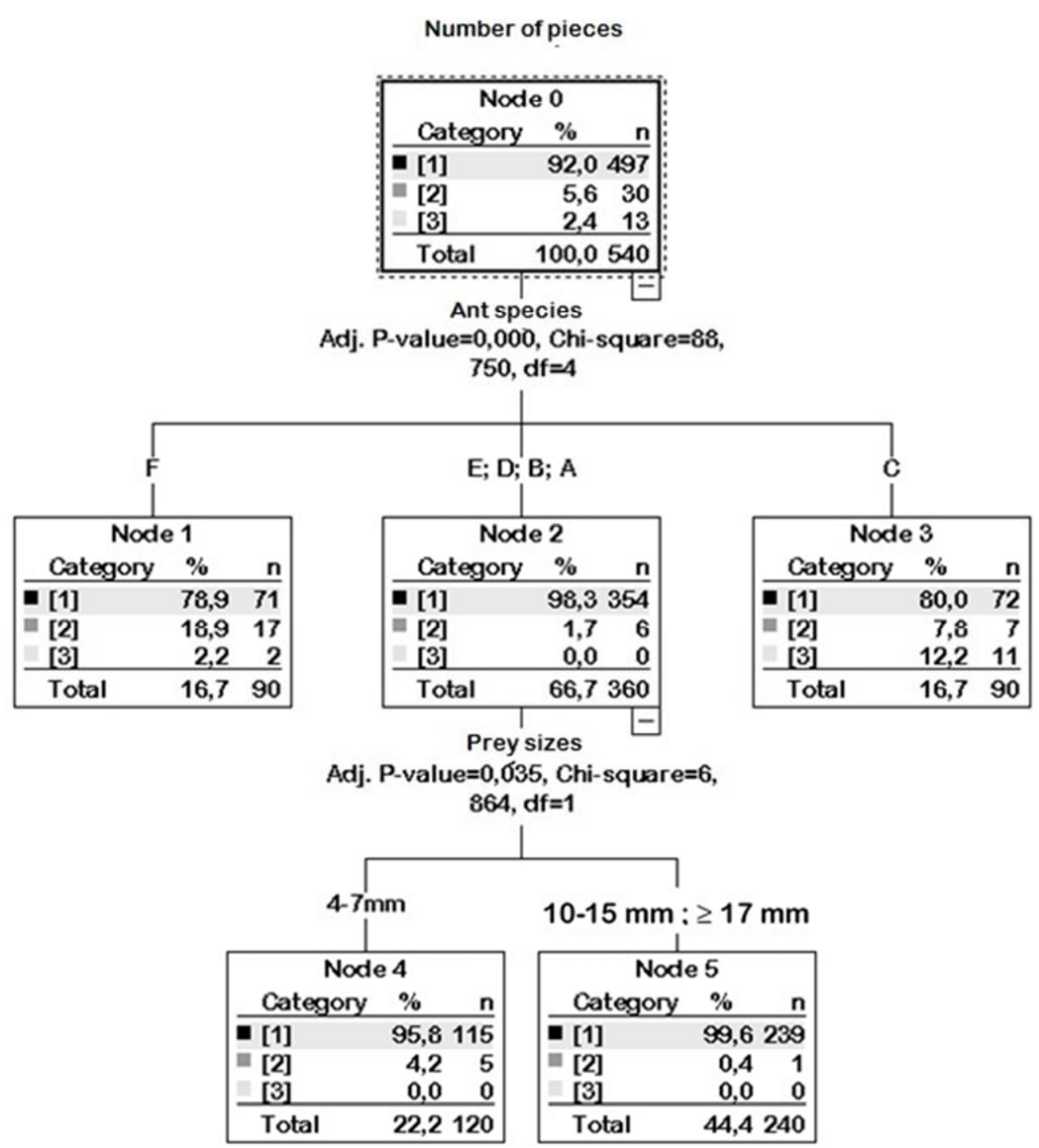

Figure 6. Trees diagrams showing hierarchical influence between number of large pieces, ant species and prey size during prey fragmentation in six tropical arboreal ants in presence of grasshoppers.

Legend of the Figures

Ant species:

A: Oecophylla longinoda; B: Tetramorium aculeatum; C: Crematogaster clariventris, D: Crematogaster sp. " stapi", E: Platythyrea conradti et F: Myrmicaria opaciventris.

Fragmentation modalities:

G: no fragmentation; H: total fragmentation into tiny piece; I: partial fragmentation where workers cut just the appendages; J: partial fragmentation into two large pieces; K: partial fragmentation into three large pieces; L: partial fragmentation into two large piece followed by fragmentation of each large pieces into tiny pieces; M: fragmentation into three large pieces followed by fragmentation of each large pieces in tiny piece.

Transport modalities:

N: solitary transport by a single worker; O: collective transport without prey fragmentation; P: collective transport after prey fragmentation into tiny pieces; Q: collective transport after partial fragmentation of appendages followed by the transport of the rest of entire prey in the nest; R: collective transport after prey fragmentation into two or three large pieces followed by the fragmentation into tiny pieces; S: collective transport of large pieces after partial fragmentation into two or three large pieces, each pieces was transported by a group of workers; T: collective transport of large pieces after partial fragmentation of prey into two or three large pieces, each large piece was transported by a single worker and U: prey escape.

Number of pieces after fragmentation:

[1]: one-piece fragment into tiny pieces or transported entirely by a collective worker in the nest; [2] and [3]: fragmentation into 2 or 3 large pieces respectively. 


\section{Discussion}

Prey fragmentation appears as a fundamental strategy to exploit large prey in ant species. In tropical ant species, small sized prey are not fragmented by species like $M$. opaciventris, $P$. conradti and $O$. longinoda and were generally transported entirely to the nest by either one worker or several workers. [10] described collective transport without fragmentation as cooperative prey retrieval strategy in which several workers cooperate to carry the unfragmented prey. Prey capture and transport without fragmentation has also been described in O. longinoda by [9]. In $P$. conradti, unfragmentation is consistent with their solitary hunting behavior [8] and the absence of elaborated nestmates recruitment when a resource is discovered [14]. When the prey size increases, the fragmentation occurred with a variable modality in relation to the level of arboreal adaptation. Collective prey retrieval was observed in $M$. opaciventris, $P$. conradti and $O$. longinoda, total fragmentation in tiny pieces in $T$. aculeatum, partial fragmentation in large pieces in $M$. opaciventris and partial fragmentation in large pieces followed by fragmentation in tiny pieces before transport in the nest was observed in $C$. clariventris. Prey size influenced the number of large pieces obtained after fragmentation; this was observed in the presence of grasshopper where 4-7 $\mathrm{mm}$ prey size were more frequently fragmented into two large pieces than 10-15 mm and $\geq 17 \mathrm{~mm}$ prey size. In fact, the cuticle of young grasshopper is softer than that of adult; consequently, during spread-eagling it's easier for workers to slice the prey in large pieces before transporting them. During fieldwork we observed that, as prey size increased, workers were helped by the major caste in polymorphic species like $C$. clariventris. During spread-eagling the majors were actively recruited and divided first adult grasshoppers in two or three large pieces, before these were further fragmented into tiny pieces by minor workers and transported. This division of labour appears to be an example of polyethism. We suggest that, this approach may reduce the energy costs invest to prey capture and transport in some arboreal ants. Tetramorium aculeatum workers systematically fragmented large prey into tiny pieces before transporting them to the nest. This result is in line with [6] who found high frequency of termites and grasshoppers cutting up in small pieces after spread-eagling in $T$. aculeatum workers. Fragmentation of large prey into tiny pieces by the arboreal ant species such as T. aculeatum, Crematogaster sp. and $C$. clariventris may facilitate prey transport by workers in compensation of their small size.

We previously observed a relationship between fragmentation strategy, transport modality and nesting habitat. Looking at nesting habitat, it appeared that ground living ant species and primitive arboreal ant are more cooperative in prey retrieval than arboreal ants [10]. We found cooperation in prey retrieval in ground-dwelling ant (M. opaciventris), primitive arboreal ant $(P$. conradti) and in some arboreal ants $(O$. longinoda). [10] suggested that prey fragmentation may be the consequence of prey consumption at capture. This study does not establish relationship between prey fragmentation and prey consumption at capture but suggest that transport modality varies with fragmentation strategy. Two fundamental strategies have been reported including solitary and collective transport $[11,15]$. Our result showed that, solitary and collective transport have some specificity depending on fragmentation pattern adopted. For, several studied ant species, single or a group of workers transport unfragmented prey ( $M$. opaciventris and $O$. longinoda). When the prey was partially fragmented, each large pieces was transported by a single worker or by a group of worker ( $M$. opaciventris). Prey were transported collectively in tiny pieces when total fragmentation occured (T. aculeatum, C. clariventris and Crematogaster sp.).

\section{Conclusion}

During prey capture, fragmentation frequency increase with prey type and prey size. In ground-dwelling ants, primitive arboreal ants and in some specialized arboreal ants, collective prey retrieval without fragmentation of small and medium prey sizes was observed. In some specialized arboreal ant, prey was partially fragmented in large pieces follow by total fragmentation in tiny pieces before transport. It seems that, prey fragmentation in tiny pieces was the most achieved strategy observed. Variation in transport modality including solitary transport by a single worker, collective transport of large pieces each by a single worker, collective transport of large pieces each by a collective worker, collective transport of tiny pieces after partial fragmentation followed or not by total fragmentation, was observed. Prey exploitation in $O$. longinoda, considered as high specialized arboreal ant is closer in many aspects to that of the ground-dwelling and primitive arboreal ant.

\section{Acknowledgements}

We thank to the Direction board of the "Institut de Recherche Agricole pour le Développement" for the permission to access in Minkoa Mayos orchard for field experimentation. The authors did not receive support from any organization for the submitted work.

\section{References}

[1] Tadu, Z. (2016). Organisation spatiale des communautés de fourmis arboricoles tropicales: rôle structurant et importance du comportement prédateur. Thèse de Doctorat, Université de Yaounde 1, Cameroun.

[2] Dejean, A., Rodríguez-Pérez, H., Carpenter, J. M., Azémar, F., \& Corbara, B. (2017). The predatory behavior of the Neotropical social wasp Polybia rejecta. Behavioral Process 140: $161-168$.

[3] Lachaud J-P., \& Dejean, A. (1994). Predatory behaviour of seed-eating ant: Brachyponera senaarensis. Entomologica Experimentalis et Applicata 72: 145-155. 
[4] Deneubourg, J. L., Aron, S., Goss, S., \& Pasteel, J. M. (1987). Error, communication and learning in ant societies. Europeen Journal of Operational Research 30: 168-172.

[5] Liefke, C., Hölldobler, B., \& Maschwitz, U. (2001). Recruitment Behavior in the Ant Genus Polyrhachis (Hymenoptera, Formicidae). Journal of Insect Behavior 14: 637-657.

[6] Djiéto-Lordon, C., Richard, F. J., Owona, C., Gibernau, M., Orivel, J., \& Dejean, A. (2001b) The Predatory Behavior of the Dominant Arboreal Ant Species Tetramorium aculeatum (Hymenoptera: Formicidae). Sociobiology 38: 1-11.

[7] Richard, F. J., Fabre, A., \& Dejean, A. (2001). Predatory behaviour in dominant arborael ant species: the case of Crematogaster sp. (Hymenoptera: Formicidae). Journal of Insect Behavior 14: 271-282.

[8] Dejean, A. (2011). Prey Capture Behavior in an Arboreal African Ponerine Ant. PLoS ONE 6: 1-7.

[9] Dejean, A. (1990). Prey capture strategy of the african weaver ant. Westview Press (edit), Boulder, Colorado, USA.

[10] Yamamoto, A., \& Ishihara, S., Ito, F. (2009). Fragmentation or transportation: mode of large-prey retrieval in arboreal and ground nesting ants. Journal of Insect Behavior 22: 1-11.
[11] Kenne, M., Schatz, B., Durand, J. L., \& Dejean, A. (2000). Hunting strategy of a generalist ant species proposed as biological control agent against termites. Entomologica Experimentalis et Applicata 94: 31-40.

[12] Tadu, Z., Djiéto-Lordon, C., Yede, Messop-Youbi, E. B., Fomena, A., \& Babin, R. (2014). Ant diversity in different cocoa agroforest habitats in the Centre Region of Cameroon. African Entomology 22: 388-404.

[13] Tadu, Z., Babin, R., Yede, Aléné, D. C., Messop-Youbi, E. B., Yede, Wouter, D. \& Djieto-Lordon, C. (2019a). Ant assemblage structure on cocoa trees in smallholder farms in the Centre Region of Cameroon. African Journal of Ecology, 00: $1-11$.

[14] Tadu, Z., Bagny Beilhe, L., Aléné, D. C., \& Djieto-Lordon, C. (2019b). Recruitment Rate of Nestmate in Six Tropical Arboreal Ants (Hymenoptera: Formicidae). Journal of Insect Behavior (32) 252-266.

[15] Djiéto-Lordon, C., Orivel, J., \& Dejean, A. (2001a). Predatory Behavior of the African Ponerine Ant Platythyrea modesta (Hymenoptera: Formicidae). Sociobiology 38: 1-13. 